\title{
A CONSTITUIÇÃO DO SUJEITO ATIVISTA DE DIREITOS HUMANOS EM COMENTÁRIOS VIRTUAIS SOBRE A MORTE DE MARIELLE FRANCO
}

\section{The Constitution of the Human Rights Activist Individual in Virtual Comments about Brazilian Politician and Activist Marielle Franco's death}

DOI: 10.14393/LL63-V36n1-2020-8

\author{
Ângela Paula Nunes Ferreira* \\ Douglas de Oliveira** \\ Regina Baracuhy ${ }^{* * *}$
}

* Doutoranda em Linguística pela Universidade Federal da Paraíba. Graduada em Direito pela Universidade Estadual da Paraíba. Graduada em Letras pela Universidade Federal de Campina Grande. ORCID: 0000-00031097-0329. E-mail: paulanunesf(AT)hotmail.com.

** Mestre em Linguística pela Universidade Federal da Paraíba. Graduado em Letras pela Universidade Vale do Acaraú. Graduado em Jornalismo pela Universidade Federal da Paraíba. ORCID: 0000-0002-2897-1883. E-mail: douglasdeoliveira55(AT)gmail.com.

*** Professora Associado Nível IV da Universidade Federal da Paraíba, onde ministra disciplinas e orienta pesquisas em nível de Graduação no Departamento de Letras Clássicas e Vernáculas (DLCV) e no Programa de Pós-graduação em Linguística (PROLING). Doutora em Linguística e Língua Portuguesa pela UNESP (Araraquara). Líder do grupo de pesquisa CIDADI. ORCID: 0000-0003-2867-6806. E-mail: mrbaracuhy(AT)hotmail.com. 
RESUMO: A morte de Marielle Franco, vereadora carioca e ativista dos Direitos Humanos, desencadeou embates discursivos na web. De um lado, seus aliados clamavam por justiça. De outro, os críticos a ironizavam e propagavam fake news que amenizavam o fato de Marielle ter sido brutalmente assassinada. Neste artigo, fruto de reflexões em nível de mestrado e doutorado no Círculo de Discussão em Análise do Discurso (CIDADI), nos propomos a analisar, à luz dos estudos discursivos foucaultianos, a constituição do sujeito ativista dos Direitos Humanos a partir do acontecimento discursivo morte de Marielle Franco. Para tanto, procedemos a uma análise arqueogenealógica dos comentários da publicação de pesar feita pelo partido "PSOL Carioca", compartilhada no perfil de facebook oficial da vereadora Marielle Franco assim que se tornou pública a sua morte. Nos comentários analisados, depreendemos, pelo menos, duas regularidades discursivas que apresentam posicionamentos sociais opostos acerca da função do sujeito ativista de Direitos Humanos, a partir das práticas divisoras que ora o subjetivam como "defensor de bandidos", ora o subjetivam como "guerreiros".

PALAVRAS-CHAVE: Direitos humanos. Estudos discursivos foucaultianos. Facebook. Marielle Franco. Processos de subjetivação.

ABSTRACT: The death of Marielle Franco, Rio de Janeiro councilwoman and human rights activist, triggered discourse clashes on the web. On the one hand, her allies clamored for justice. On the other hand, critics mocked her and spread fake news that muffled the fact that she was brutally murdered. This article is the result of reflections at the master's and doctoral level in the Circle of Discussions on Discourse Analysis. Drawing on Foucauldian discourse analysis, it analyzes the constitution of the human rights activist individual taking into account Marielle Franco's death as a discursive event. To this end, we archeogenealogically analyze the comments on the note of regret by the left-wing party PSOL Carioca that was shared on her official Facebook account when her death became public. At least two discursive regularities show in the comments, each with opposite stances towards the role of the human rights activist, as the dividing practices subjectify the activist as either a "protector of criminals" or a "warrior".

KEYWORDS: Human rights. Foucauldian discourse analysis. Facebook. Marielle Franco. Subjectification processes. 


\section{Introdução}

- Marielle!

- Presente!

Marielle. Nome que nem precisa de sobrenomes para convocar a memória da mulher que o carregou na identidade, nos pleitos e nas lutas. Nome de guerra que ganhou fama em condições igualmente bélicas, após o ataque mortal que the silenciou, tomando-lhe a vida à queima-roupa. A presença evocada faz-nos lembrar de um passado que parecia adormecido. O livro Cova 312, da jornalista Daniela Arbex (2015, p. 342), percorre uma jornada pelos recônditos da Ditadura Militar para investigar o suposto suicídio de um guerrilheiro e finaliza seu percurso com as seguintes palavras:

Uma certeza se consolida: esquecer é impossível. E se centenas de brasileiros tiveram suas vozes silenciadas, nós continuaremos a lembrá-los, um a um, falando em seus nomes.

- Milton Soares de Castro!

- PRESENTE!

O silenciamento provocado pelos estrondosos tiros que vitimaram fatalmente a vereadora Marielle Franco (PSOL-RJ) e o motorista Anderson Pedro Gomes dizem muito sobre a sociedade em que vivemos. Nascida e criada no Complexo da Maré, uma das regiões mais perigosas do Rio de Janeiro, e eleita em 2016 com 46.502 votos, Marielle era ativista dos Direitos Humanos, não apenas em projetos externos à política partidária, mas também na Câmara Municipal. Nessa instituição, presidia a Comissão da Mulher e, no mês anterior ao da sua morte, fora nomeada relatora da comissão que fiscalizaria a intervenção federal das Forças Armadas na segurança pública da cidade.

A vereadora denunciava no púlpito e nas redes sociais os casos de violência entranhados nas favelas cariocas. Considerava a intervenção militar uma "farsa" associada à "imagem da cúpula da segurança pública, com a salvação do PMDB, com a indústria do armamentismo". Também afrontava abusos de policiais, como os cometidos pelo 41 o batalhão da PM contra moradores da favela de Acari: "Nesta semana dois jovens foram mortos e jogados em um valão. Hoje a polícia andou pelas ruas ameaçando os moradores. 
Acontece desde sempre e com a intervenção ficou ainda pior" (RANGEL; VETTORAZZO; FRANCO, 2018).

Marielle se colocava ao lado dos desvalidos, dos marginalizados. Defendia os direitos dos moradores das favelas, das mulheres de periferia, dos jovens negros - estes que são assassinados a cada 23 minutos no Brasil (ESCÓSSIA, 2016). Mulher, negra, cabelos crespos. Corpo que ainda precisa muito lutar para escapar das injustiças sociais. Era com esse corpo que a vereadora punha nas pautas políticas a questão dos Direitos Humanos. E, por isso, como muitos dos que brigam por esses direitos, ela era rechaçada por uma parcela conservadora da população, por aqueles que insistem em atrelar ao "ativista dos direitos humanos" a figura de "defensor de bandido". O corpo de Marielle não habita mais entre nós nem entre os periféricos que a elegeram. Entretanto, sua memória permanece presente e, em nome dela, mundo afora, as pessoas têm buscado evidenciar o caráter digno e a necessidade pujante do legado daqueles que se munem dos Direitos Humanos na guerra contra a violência - seja física, seja simbólica.

Assim como Marielle Franco, Michel Foucault, cujos postulados seguimos na construção deste artigo, interessava-se pelos desvalidos e marginalizados. Ao estudar as relações de poder que permeiam a sociedade, o filósofo partia da perspectiva não das instituições, em seus mandos e desmandos, mas daqueles nos quais o poder incidia com brutalidade, conduzindo suas condutas e negando-lhes a credibilidade da voz. A partir desse antagonismo de estratégias (FOUCAULT, 1995), o intelectual analisava a loucura, a delinquência, a anormalidade. "Cartógrafo das margens", como o define o historiador Durval Muniz de Albuquerque (2008), Foucault descreveu as condições históricas que determinaram a constituição dos sujeitos loucos, delinquentes, anormais. Que relações de saber-poder transpassam esse processo de construção de subjetividades?

Partindo dessa indagação, pretendemos operar uma análise discursiva de alguns dos comentários virtuais da publicação do partido "PSOL carioca", compartilhada no Facebook oficial da vereadora Marielle Franco, assim que se tornou pública a sua morte. Até 30/10/2019, a publicação possuía 1.691 comentários.

Buscamos compreender os processos de constituição do sujeito ativista dos Direitos Humanos e das identidades nas quais se confrontam esquecimentos e memórias cerceadas 
por relações de força. Para isso, utilizamos o arcabouço conceitual dos estudos discursivos foucaultianos principalmente no que concerne às noções de acontecimento e de processos de subjetivação / objetivação.

\section{Pressupostos teóricos}

A história tradicional nos serve de ilusão. Ilusão de que superamos erros e ignorâncias, de que o passado não retorna, de que evoluímos em espécie e em pensamento (FOUCAULT, 2010). Ela se constrói a partir do olhar do historiador sobre os grandes acontecimentos, aqueles feitos heroicos de reis e imperadores. É a história oficial, a espuma sob a qual camadas de diferentes se escondem - ou são escondidas, caladas.

Inspirado em Jacques Le Goff, Michel de Certeau e Pierre Nora, expoentes da Nova História na década de 60 na França, Michel Foucault desenvolveu suas pesquisas buscando as singularidades dos acontecimentos que não constavam nas linhas cronológicas da história linear. Ele se autodenominava "diagnosticador do presente" e acreditava que sua função era a de "pelo gesto mínimo que consiste em deslocar o olhar, visibilizar o que é invisível, fazer aparecer o que está próximo, tão imediato, tão intimamente ligado a nós que, exatamente por isso, não o vemos" (FOUCAULT, 1978, p. 594 apud ARTIÈRES, 2004, p. 22). Esse papel de pinçar as raridades e as rupturas dos acontecimentos o distanciou da noção de continuidade, enfatizada pelos historiadores tradicionais e o levou a aderir ao princípio da descontinuidade como uma maneira de visibilizar os recônditos da história.

Para refletirmos sobre esse princípio elementar das análises foucaultianas, consideremos as referências feitas, nos parágrafos iniciais deste artigo, ao período da Ditadura Militar no Brasil. Que conexão podemos estabelecer entre as décadas que nos antecederam e as discussões acendidas pela morte de Marielle Franco além do termo "Presente!"? Ora, o embate entre a guerrilha e os militares construiu identidades para ambos os sujeitos sociais. Uma delas se relaciona à "balbúrdia" e à "depredação" provocadas por aqueles que resistiam à censura, ao poder hegemônico. Eram vistos, por vezes, como perturbadores da ordem social, como bandidos. Mais de cinquenta anos após o golpe de 1964, acontecimentos retornam, sob condições distintas e singulares; condições estas que determinaram sua repercussão internacional. Em plenos 2018, o "cálice de vinho tinto e de 
sangue" não se afastou de uma vereadora que lutava politicamente pelas causas de pobres e negros. Silenciada mortalmente pela censura, sua imagem foi associada à de "defensora de marginais" - no sentido pejorativo da palavra. A investigação do assassinato de Marielle levou a dois suspeitos; ambos atuaram como policiais militares. A repressão, portanto, não cessou, como a história tradicional nos faz crer. A continuidade é uma farsa; o que existem são descontinuidades que irrompem no curso da história, de acordo com condições específicas. Como nos diz Foucault (1999, p. 26), "o novo não está no que é dito, mas no acontecimento de sua volta".

Ao pensarmos assim, recusamos a ideia de que "o sujeito é originário de todo o devir e de toda prática", do "tempo concebido em termos de totalização, onde as revoluções jamais passam de tomadas de consciência" (FOUCAULT, 2010, p. 14). Percebemos a existência não de um sujeito constituinte, mas de um sujeito constituído pela história, cuja identidade é esboçada pelos acontecimentos em que se insere. Para que analisemos tais acontecimentos sob uma perspectiva foucaultiana, devemos organizá-los em "unidades, conjuntos, séries, relações" (FOUCAULT, 2010, p. 7) e escavar as condições que possibilitaram sua irrupção histórica. Interroguemo-nos, então, sobre as relações de saber-poder que se entrelaçaram e provocaram a morte de Marielle e, em seguida, sobre os fatores que permitiram sua insurgência em níveis internacionais.

Para a primeira resposta, a entrevista de Bruno Cava, professor de Filosofia e estudioso de Michel Foucault, ao Instituto Humanitas Unisinos (IHU) nos parece pertinente:

Bruno Cava: "O acontecimento-Marielle expressa os problemas em diferentes níveis: expressa o problema das minorias, inclusive das que nos habitam como devires, a partir do corpo de mulher negra, lésbica, da favela, vereadora e liderança política. Além de força de expressão desses problemas, funciona enquanto nome próprio e força impessoal, e precisa se mostrar indomável, seja em relação à redução a dado estatístico ou estrutural para reconfirmar o nosso próprio horror e impotência, seja à simples cobrança pela punição dos culpados, que, como os Lee Oswalds ou delegados Fleury de ocasião, podem ser descartados sem grandes abalos. O esquadrão da morte existe no interior não só de uma economia política, como também de uma economia da subjetividade". (FACHIN, 2018)

O assassinato de Marielle irrompeu, de maneira sintomática, em meio ao racismo, desigualdade social e intolerância que assola nosso país. Escancarou, desse modo, a 
perenidade de relações de poder aparentemente superadas na ilusão de uma historiografia linear e evolutiva. Entretanto, as resistências se mostram novamente presentes, de posse de instrumentos ainda mais aperfeiçoados. As redes digitais permitiram a emergência de variados protestos em torno da figura de Marielle. Foram hashtags no Twitter, memes, publicidades, notícias e reportagens. Debaixo desse acontecimento matricial que ganhou as manchetes do mundo, há um "estrato de acontecimentos difusos, 'atmosféricos', policéfalos que, afinal, determinam, e profundamente, a história do mundo" (FOUCAULT, 2000, p. 292). Abaixo da superfície, o iceberg é bem maior do que sua ínfima ponta; lá se escondem, pelo menos, dois conjuntos de acontecimentos estratificados. O primeiro deles se refere a negros, mulheres e marginalizados violentados e mortos todos os dias no Brasil que figuram apenas como meros dados estatísticos ou aparecem por ligeiros segundos em telejornais locais. 0 outro conjunto engloba os enunciados que se multiplicaram inumeravelmente na mídia e, devido à exterioridade e ao acúmulo de que se constituem, conquistaram o estatuto de acontecimentos enunciativos ou discursivos.

\begin{abstract}
A análise enunciativa tenta liberar-se, para restituir os enunciados à sua pura dispersão; para analisá-los em uma exterioridade sem dúvida paradoxal, já que não remete a nenhuma forma adversa de interioridade; para considerálos em sua descontinuidade; [...] para apreender sua própria irrupção no lugar e no momento em que se produziu; para reencontrar sua incidência de acontecimento. (FOUCAULT, 2010, p. 137-138)
\end{abstract}

Unidos em rede, os ativistas dos direitos humanos reverberaram suas lutas na forma de uma pluralidade de enunciados-acontecimentos associados ao caso Marielle Franco. Segundo Manuel Castells, as resistências que se propagam no virtual partem também de uma mobilização emocional derivada da indignação provocada pela injustiça. Somado a esse componente, há a esperança "de uma possível mudança em função de exemplos de revoltas exitosas em outras partes do mundo, cada qual inspirando a seguinte por meio de imagens e mensagens em rede pela internet" (CASTELLS, 2013, p. 159).

Além dos enunciados-acontecimentos que prestaram homenagem e apoio a Marielle, outras mensagens se posicionaram contra a vereadora, emanando calúnias, difamações e injúrias a sua memória. A quantidade de fake news produzidas e compartilhadas em rede teve grande destaque nas mídias digitais. Os comentários de Facebook sobre o papel do sujeito 
ativista dos direitos humanos, analisados neste artigo, são exemplos concretos desses enunciados. Concedendo-lhes tratamento de acontecimento discursivo, enquanto materializações efetivas das relações de saber-poder que circulam na sociedade brasileira, demonstraremos sua relevância para a compreensão da constituição da identidade dos sujeitos na história.

Em seu artigo "O sujeito e o poder", Michel Foucault (1995, p.273) destaca que o objetivo dos seus estudos, ao longo dos últimos 20 anos, foi "criar uma história dos diferentes modos pelos quais, em nossa cultura, os seres humanos tornaram-se sujeitos". Em seguida, Foucault apresenta os modos de objetivação, através do quais os seres humanos se transformam em sujeitos, que correspondem às suas três fases de estudo: a arqueologia do saber, a genealogia do poder e a genealogia da ética. Os modos de objetivação são os seguintes: os que tentam atingir o estatuto de ciência, como, por exemplo, a objetivação do sujeito do discurso na "grammaire générale", na filologia, na linguística, na economia; as práticas divisoras que dividem o sujeito no seu interior e em relação aos outros, como o louco e o são, o doente e o sadio, os criminosos e os "cidadãos de bem"; por fim, como o indivíduo torna-se ele próprio um sujeito a partir do conhecimento sobre sua sexualidade.

Enquanto estava viva, a vereadora Marielle Franco se subjetivava a partir da escrita de si em suas redes sociais, em suas arguições públicas, da confissão que se dava cotidianamente na tribuna da Câmara dos Vereadores do Rio de Janeiro (RJ), a partir de atos de resistência, ocupando a posição-sujeito de mulher, negra, defensora dos Direitos Humanos.

O partido (PSOL carioca) ao qual Marielle Franco era filiada, horas após a confirmação do seu assassinato, emitiu uma nota oficial no facebook, e compartilhou a publicação na página oficial de Marielle. A nota continha a seguinte declaração:

Nota do PSOL: Marielle Franco, presente!

Em 14/03/2019

O Partido Socialismo e Liberdade vem a público manifestar seu pesar diante do assassinato da vereadora Marielle Franco e de Anderson Pedro Gomes, motorista que a acompanhava.

Nota do PSOL: Marielle Presente!

Estamos ao lado dos familiares, amigos, assessores e dirigentes partidários do PSOL/RJ nesse momento de dor e indignação. A atuação de Marielle como vereadora e ativista dos direitos humanos orgulha toda a militância do 
PSOL e será honrada na continuidade de sua luta. Não podemos descartar a hipótese de crime político, ou seja, uma execução. Marielle tinha acabado de denunciar a ação brutal e truculenta da PM na região do Irajá, na comunidade de Acari. Além disso, as características do crime com um carro emparelhando com o veículo onde estava a vereadora, efetuando muitos disparos e fugindo em seguida reforçam essa possibilidade. Por isso, exigimos apuração imediata e rigorosa desse crime hediondo. Não nos calaremos!

Marielle, presente!

Partido Socialismo e Liberdade

14 de março de 2018.

A nota compartilhada no Facebook oficial da vereadora Marielle Franco, assim que se tornou pública a sua morte, possuía 1.691 comentários até 30/10/2019.

$\mathrm{Na}$ nossa sociedade, são considerados ativistas dos Direitos Humanos aqueles indivíduos que agem em prol da promoção e proteção desses direitos fundamentais.

Os direitos humanos consistem em um conjunto de direitos considerado indispensável para uma vida humana pautada na liberdade, igualdade e dignidade. Os direitos humanos são os direitos essenciais e indispensáveis à vida digna. Não há um rol predeterminado desse conjunto mínimo de direitos essenciais a uma vida digna. As necessidades humanas variam e, de acordo com o contexto histórico de uma época, novas demandas sociais são traduzidas juridicamente e inseridas na lista dos direitos humanos. (RAMOS, 2018, p. 28)

Em que pese a abrangência do conceito de Direitos Humanos, que deve alcançar todo indivíduo, pelo simples fato de pertencer a espécie humana, no nosso país, o imaginário coletivo costuma associar os Direitos Humanos aos direitos dos "bandidos". O que ocorre é que aqueles indivíduos que se enquadram em algum grupo minoritário são os principais alvos do desrespeito aos Direitos Humanos. Desse modo, os defensores dos Direitos Humanos são comumente associados a esses grupos minoritários compostos por negros, mulheres, favelados, LGBTS, presidiários etc. e ainda, a partidos políticos de esquerda.

Na nossa sociedade, os seres humanos, na vida e na morte, costumam ser valorizados pelos papéis sociais que exercem. No senso comum, a vida de um "cidadão de bem" tem mais valor do que a vida de alguém considerado criminoso. Assim, diante da morte de um indivíduo, é comum que surjam indagações acerca da conduta social da vítima. No caso de bandidos, criou-se uma compreensão de que não é necessário se aprofundar ou investigar as 
causas da sua morte, ou buscar justiça nesses casos, já que se trata de indivíduo considerado inferior aos demais, pela prática de crimes.

Essa compreensão se ajusta a uma formação discursiva que compreende que as vidas de determinadas pessoas consideradas "cidadãos de bem" devem ser mais valorizadas do que a daquelas pertencentes a grupos marginalizados, criminosos, drogados, e que, portanto, se colocam de forma contrária aos Direitos Humanos, que consideram a essencialidade de direitos que devem ser protegidos, comuns a todos os indivíduos pelo fato de pertencerem à espécie humana, independente de raça, credo ou nacionalidade.

Essa compreensão se confronta com uma formação discursiva através da qual se compreende que toda vida humana deve ser preservada, independentemente de raça, credo ou nacionalidade, e que defende que a dignidade humana deve ser preservada, independentemente de quaisquer delitos cometidos.

Nos comentários abaixo da postagem do PSOL acerca da morte de Marielle Franco, o sujeito ativista dos Direitos Humanos foi constituído principalmente a partir de práticas divisoras. Os enunciados materializados nos comentários se filiam a duas formações discursivas diversas. Por um lado, temos comentários que se associam a uma formação discursiva que se opõe à defesa dos Direitos Humanos das minorias. Por outro lado, uma formação discursiva que enfatiza a necessidade fundamental dos Direitos Humanos.

\section{Metodologia}

O corpus é constituído por 24 comentários selecionados e agrupados a partir do critério de regularidade discursiva. Conforme Foucault (2010), os enunciados podem ser organizados segundo a categoria metodológica da formação discursiva, que consiste na identificação de semelhanças em meio às dispersões discursivas. Após encontrarmos termos linguísticos e posições sociais que se alinham e demonstram incidência recorrente nos comentários, classificamos os comentários de acordo com suas regularidades, o que nos levou à constatação de duas identidades dicotômicas atribuídas aos ativistas de Direitos Humanos: a primeira, negativa, associa esses sujeitos ao crime; a segunda, positiva, enxergaos como cidadãos que buscam justiça social. 
Após selecionarmos os comentários de acordo com os critérios expressos acima, adotamos o método arqueogenealógico foucaultiano, proposto e sistematizado por Gregolin (2015), para fins de análise. Esse trabalho que une a arqueologia dos saberes e a genealogia dos poderes nos permite investigar quais discursos concorrem para a emergência de enunciados que refletem e instituem relações históricas de poder, visto que, conforme nos assevera Foucault (2014, p. 31), "não há relação de poder sem constituição correlata de um campo de saber, nem saber que não suponha e não constitua ao mesmo tempo relações de poder".

\section{Resultados}

Nos comentários analisados, depreendemos, pelo menos, duas regularidades discursivas que se digladiam e evidenciam posicionamentos sociais opostos acerca da função do sujeito ativista de Direitos Humanos. A primeira regularidade apresenta uma visão acusatória em relação à Marielle Franco, pautando-se no argumento do senso comum que enquadra aqueles que lutam pelos Direitos Humanos como "defensores de bandidos". Já a segunda regularidade reveste a vereadora sob o signo de "guerreira" e aplaude sua atuação na política e nas reivindicações sociais das minorias.

Cada uma das regularidades presentes nos enunciados movimenta os discursos em torno de Marielle Franco de maneira diferente, atribuindo-lhe características negativas ou positivas de acordo com as especificidades dos processos de subjetivação concernentes aos comentários. Ao pensarmos com Michel Foucault, entendemos que a subjetivação é um processo permanente de gestação de identidades inacabadas que se constituem conforme as vontades de verdade de cada época (FOUCAULT, 2004). Nesse sentido, mesmo que o corpo de Marielle repouse em um cemitério no Rio de Janeiro, sua posição-sujeito continua a ser discursivizada. Esse incessante movimento enunciativo materializa as percepções sobre aqueles que assumem o papel social de ativista dos Direitos Humanos e ainda sobrevivem entre nós, o que pode tolher ou fomentar suas ações conforme as relações de poder instituídas pelos discursos evocados.

Inicialmente, analisaremos a primeira regularidade discursiva, que aponta a morte de Marielle como consequência de sua atuação político-social ou rotula o ativista dos Direitos 
Humanos como "defensor de bandido". Os comentários reunidos a seguir utilizam o recurso argumentativo da ironia para fortalecer esse processo de subjetivação:

Meus sentimentos aos familiares e amigos. A morte e sempre triste. Principalmente a violenta.

Pesames prestados, fica aqui a minha pergunta:

Vcs agora irão prestar solidariedade a familia da Marielle, ou aos assassinos (vulgos; vitimas da sociedade) q tanto defendem? Lembrando q a Marielle nao tera direito a 2 chance! $:-\%$

Espero que os executores sejam capturados, sem qualquer tipo de abuso de autoridade ou tortura. Além disso, sejam também ressocializados da melhor forma possível e digna no cumprimento da sanção penal, uma vez que eles são vítimas da sociedade capitalista opressora e merecem uma segunda chance de viverem em sociedade.

\author{
Que os assassinos da vereadora do \\ PSOL sejam tratados com dignidade \\ e respeito! Ao invés de serem \\ presos, sejam reintegrados a \\ sociedade, pois a cadeia não \\ reeduca ninguém e eles são apenas \\ seres humanos, vítimas da \\ sociedade opressora e sem \\ Oportunidade! Vítimas do afeto \\ capitalista!
}

Lembrando que os assassinos são meras vítimas da sociedade, não devem ser tratados como tal, apenas não tiveram oportunidade na vida coitados... não os julguem sem conhecerem...

Orem pelos bandidos oprimidos que a mataram, são vítimas da sociedade!

Figura 1. Comentários que usam o recurso da ironia

Fonte: facebook.com/MarielleFrancoPSOL.

Ao utilizarem a ironia, os usuários convocam discursos veiculados pelos ativistas dos Direitos Humanos e os deslocam conforme a modalidade enunciativa da qual emanam os comentários acima. Os termos "vítimas da sociedade", "apenas seres humanos", "sociedade opressora", "segunda chance" são comumente enunciados por aqueles que defendem a dignidade humana e enxergam a teia complexa de desigualdade de oportunidades que constitui os indivíduos, a exemplo das diferenças de acesso à educação, à saúde, ao trabalho, à moradia, e ao lazer. Entretanto, ao serem incorporados a esses comentários, tais termos revestem-se de ironia, visto que os localizam em uma modalidade enunciativa contrária à dos ativistas dos Direitos Humanos. Para Foucault (2010, p. 61), as diversas modalidades de enunciação, "em lugar de remeterem à síntese ou à função unificante de um sujeito, 
manifestam sua dispersão: nos diversos status, nos diversos lugares, nas diversas posições que pode ocupar ou receber quando exerce um discurso, na descontinuidade dos planos de onde fala".

Convém refletirmos também acerca de quais saberes desaguam na emergência desses enunciados e tornam possíveis suas realizações, correlações e consequências. Ao ironizarem as possibilidades de reeducação do criminoso e de sua reinserção na sociedade, os usuários convocam a construção histórica do delinquente enquanto inimigo público. O sentimento de vingança contra os criminosos está entranhado no Ocidente desde os antigos e clássicos suplícios aplicados aos desafiadores da ordem (enforcamentos, esquartejamentos, fogueira, pelourinho etc.) até o aparecimento de prisões, cujas celas abrigam uma quantidade de condenados superior à sua capacidade (FOUCAULT, 2015). Esse sentimento que perpassa a função enunciativa dos comentários analisados encontra legitimidade tanto em discursos sobre a punição - como a fala proferida por Beaumetz na Assembleia Constituinte em outubro de 1789, "no momento em que recomeçou a ser elaborada a organização penal na França" (FOUCAULT, 2015, p. 41) - quanto em produtos midiáticos sensacionalistas que desrespeitam os Direitos Humanos e relegam a posição de "defensor de bandido" aos seus ativistas (ANGRIMANI, 1995). 


\begin{abstract}
A vereadora assassinada foi mais uma das 6378 vítimas da violência no Rio de Janeiro.

Com todo respeito a dor da família e amigos, eu não faço distinção entre ela, o motorista do carro, que também foi assassinado e das outras 6376 vítimas, e, ressalte-se, dentre essas vítimas, 136 policiais militares, mortos em ação ou em dias de folga.

Nascida e criada dentro do Complexo de Favelas da Maré, Marielli, SUSPEITA-SE, elegeu-se vereadora com mais de 46 mil votos. com o dinheiro do Comando Vermelho, que é quem comanda do tráfico de drogas nesse local.
\end{abstract}

\section{Engajada com bandidos!!!}

q pena, como a companheira vai defender bandido? quero ver o psol e a família dela defender o assassino.

Foda-se ela, defendia bandidos com os direitos dos manos.
Fórmula pra acabar com a criminalidade no Brasil:

10) executem todos os defensores dos direitos humanos que qualificam bandidinhos como humanos é cidadãos brasileiros

2o) executem todos os promotores públicos que entendem que bandido tem os mesmos direitos perante a constituição

Depois disto resolvido passem pra outra fase

3o) executem todos os chefes de facções

40) executem todos os idiotas que trabalham para os chefes

E pra finalizar.....

5o) executem toda a imprensa que fica a favor dos direitos humanos Pronto. Tá resolvido o problema da criminalidade no Brasil

PS.: executem no SPC viu pessoal....

Tirem o chapeu pros policiais mortos pelo trafico,que essa meliante amava....

\section{QUEM VAI DEFENDER OS DIREITOS} DOS MANOS AGORA!!!

Figura 2. Comentários que acusam Marielle de engajamento com bandidos

Fonte: facebook.com/MarielleFrancoPSOL.

A partir da prática divisora que segrega os seres humanos e os objetivam como cidadãos ou bandidos ("bandidinhos como humanos e cidadãos brasileiros") e da emergência do enunciado "Direito dos Manos", produzido a partir de uma reformulação ligada a um campo associado que abrange a linguagem de periferia, o ativista dos Direitos Humanos é subjetivado como aquele ou aquela "engajada com bandidos". 
O binarismo provocado pelas práticas divisoras também se materializa nas referências ao discurso religioso, conforme observamos na figura 3. Entre o céu e o inferno, o santo e o pecador, o puro e o impuro, há espaços para julgamentos e enquadramentos que partem de regimes de verdade construídos no decorrer da história. "A religião é o ópio do povo": a clássica frase de Karl Marx, um dos principais representantes de algumas políticas de esquerda, leva a uma oposição entre o "lado certo" e o "lado errado", entre crer ou não crer em uma força divina, dogmática e institucionalizada. Os usuários acima, partindo de "verdades de fé" concretizadas em paráfrases de discursos bíblicos, apartam-se dos "vagabundos", "criminosos" e "pessoas das favelas" ao se considerarem "cidadãos de bens". Traçam, assim, o limite histórico entre a direita - representada pela religião - e a esquerda representada pelo PSOL (Partido Socialismo e Liberdade) e pelos ativistas de Direitos Humanos -, atribuindo a cada posição-sujeito um valor perante o bem ou o mal. Associa-se novamente Marielle e aqueles que defendem a dignidade humana a características negativas - agora diante de Deus - com base em regimes de verdade que não interpretam a Declaração Universal dos Direitos Humanos como um documento direcionado a todos os cidadãos, mas somente aos "criminosos". Isso acontece porque:

A verdade é deste mundo; ela é produzida nele graças a múltiplas coerções e nele produz efeitos regulamentados de poder. Cada sociedade tem seu regime de verdade, sua "política geral" de verdade: isto é, os tipos de discurso que ela acolhe e faz funcionar como verdadeiros; os mecanismos e as instâncias que permitem distinguir os enunciados verdadeiros dos falsos, a maneira como se sanciona uns e outros; as técnicas e os procedimentos que são valorizados para a obtenção da verdade; o estatuto daqueles que têm o encargo de dizer o que funciona como verdadeiro. (FOUCAULT, 2005, p. 16, grifos nossos) 
Na Bíblia está escrito que aquilo que o homem plantar isso colherá. Infelizmente a Vereadora Marielle defendia criminosos e foras da lei que a sociedade repudia. Agora está colhendo o que plantou recebendo o repúdio dos cidadãos de bens. Aquilo que o homem plantar isso colherá. \#BOLSONAR02018 PRESIDENTE DO BRASIL.

Que possa descansar em paz mas infelizmente está do lado errado perante a nosso Senhor Jesus Cristo!
Ela colheu o que plantou, foi pro lugar dos vagabundos que ela defende.

A polícia tem que deixar essas pessoas das favelas se forder nas maos de criminosos, e mais uma vítima do próprio VENENO quem cria cobrá morre picado, coisa nenhuma esquerdista comunista psoienta , que Deus tenha misericórdia de sua alma e a acolha , mais político vive da desgraça alheia tornando as pessoas sem cérebro mais desgraçadas do que já é ............só recordando $A O$ PSOL DE NÃO ESQUECER DOS DIREITOS QUE OS ASSASSINOS DELA DEVA TER É FEIJOADA AOS SÁBADOS NA CADEIA NÃO É PSOL

Figura 3. Comentários que fazem alusão ao discurso religioso.

Fonte: facebook.com/MarielleFrancoPSOL.

A segunda regularidade, reunida na figura 4, apresenta uma visão positiva do ativista dos Direitos Humanos ao revestir a vereadora Marielle Franco sob o signo de "guerreira" e aplaudir sua atuação na política e nas reivindicações sociais das minorias. Os comentários selecionados discursivizam a morte de Marielle como "atrocidade", associando-a a sua tentativa de "fazer o nosso Brasil melhor". A vereadora é adjetivada como "guerreira", "mulher negra e guerreira", "mulher maravilhosa", "nossa guerreira", sendo subjetivada de modo positivo. Os comentários evidenciam lamento pela morte da vereadora e, sobretudo, subjetivam o sujeito ativista dos Direitos Humanos como representante de outras vozes ("A morte não cala mil vozes mil!", "Nasceram mais um milhão de Marielles"). 


\section{Lamentável tal atrocidade!}

\author{
Não MESMO! Executaram-na. \\ Nasceram mais um milhão de \\ Marielles! Não deixaremos morrer \\ nem essa notícia, nem a justiça, \\ muito menos suas causas! É \\ inacreditável!
}

\section{Que Deus te conceda um bom lugar querreira!!!!}

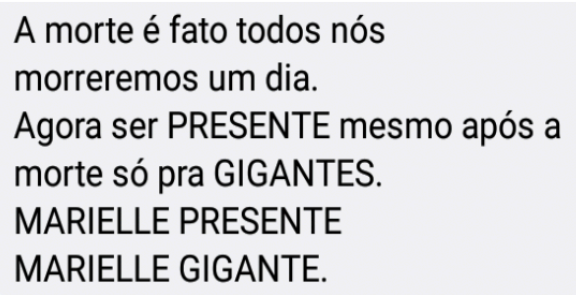

A morte é fato todos nós morreremos um dia. Agora ser PRESENTE mesmo após a morte só pra GIGANTES. MARIELLE PRESENTE MARIELLE GIGANTE.

Os que amamos não morrem, eles partem antes de nós! A morte não cala Mil Vozes Mil!

\section{Que Deus possa confortar toda a família e amigos mulher negra e guerreira mais um mulher maravilhosa que morreu pro tenta fazer o nosso Brasil melhor não só o Brasil mais sim o mundo melhor Viva pra sempre marielle nossa guerreira em nossos corações}

Muito triste sempre acompanha seu trabalho mulher guerreira vai em páz ao colo do pai

\section{Era uma mulher batalhadora por justiça}

Figura 4. Comentários que defendem a atuação do ativista de Direitos Humanos.

$$
\text { Fonte: facebook.com/MarielleFrancoPSOL }
$$

\section{Considerações finais}

A análise dos comentários postados na publicação de pesar produzida pelo PSOL e compartilhada na página do Facebook da vereadora Marielle Franco evidencia as vontades de verdade que perpassam a temática dos Direitos Humanos e resultam na constituição dicotômica do sujeito ativista a partir das práticas divisoras que ora o constituem como "defensor de bandidos", ora o constituem como "guerreiros".

Nos comentários analisados, emergem, pelo menos, duas regularidades discursivas que apresentam posicionamentos sociais opostos acerca da função do sujeito ativista de Direitos Humanos. A primeira regularidade, com maior recorrência, apresenta uma visão negativa do ativismo em Direitos Humanos, a partir do argumento do senso comum que enquadra aqueles que lutam pelos Direitos Humanos como "defensores de bandidos" ou mais ainda, "engajada com bandidos". Na segunda regularidade, o ativismo é discursivizado de maneira positiva, por exigir coragem para reivindicar em nome das minorias sociais e 
enfrentar os poderes constituídos, como no caso de Marielle, que teve a vida ceifada de forma brutal, por se subjetivar como mulher negra, pobre, lésbica, resistir aos poderes hegemônicos, e defender aqueles aos quais o Estado nega cotidianamente direitos fundamentais.

\section{Referências}

ALBUQUERQUE, D. M. de; VEIGA-NETO, A.; SOUZA FILHO, A. Uma cartografia das margens. In: ALBUQUeRQue JUNIOR, D. M. de.; VEIGA-NETO, A.; SOUZA FILHO, A. (Org.). Cartografias de Foucault. Belo Horizonte: Autêntica, 2008. p. 9-12

ANGRIMANI, D. Espreme que sai sangue. São Paulo: Summus, 1995.

ARBEX, D. Cova 312. São Paulo: Geração Editorial, 2015.

ARTIÈRES, P. Dizer a atualidade: o trabalho diagnóstico em Michel Foucault. In: GROS, F. (Org.). Foucault: a coragem da verdade. São Paulo: Parábola Editorial, 2004. p. 15-37.

CASTELLS, M. Redes de indignação e esperança: movimentos sociais na era da Internet. 1. ed. Rio de Janeiro: Jorge Zahar Editor, 2013.

ESCÓSSIA, F. A cada 23 minutos, um jovem negro é assassinado no país, diz CPI. BBC Brasil, 2016. Disponível em: https://www.bbc.com/portuguese/brasil-36461295. Acesso em: 25 out. 2019.

FACHIN, P. "Quem matou Marielle?" Entrevista especial com Bruno Cava, Marcelo Castañeda e Giuseppe Cocco. Instituto HumanitasUnisinos, 2018. Disponível em: http://www.ihu.unisinos.br/159-noticias/entrevistas/577132-a-morte-de-marielle-francocomo-uma-reacao-da-mafia-do-poder-carioca-entrevista-especial-com-giuseppe-coccobruno-cava-e-marcelo-castaneda. Acesso em: 20 ago. 2019.

FOUCAULT, M. A Arqueologia do Saber. 7.ed. Rio de Janeiro: Forense universitária, 2010.

FOUCAULT, M. A ordem do discurso. São Paulo: Loyola, 1999.

FOUCAULT, M. A Sociedade Punitiva: curso no Collège de France (1972-1973). 1. ed. Trad. de Ivone C. Benedetti. São Paulo: WMF Martins Fontes, 2015.

FOUCAULT, M. Michel Foucault, uma entrevista: sexo, poder e a política da identidade. Verve, n. 5, p. 260-277, 2004.

FOUCAULT, M. Microfísica do Poder. 21 ed. Tradução Roberto Machado. Rio de Janeiro: Graal, 2005.

FOUCAULT, M. O sujeito e o poder. In: DREYFUS, H.; RABINOW, P. Michel Foucault, uma trajetória filosófica. Para além do estruturalismo e da hermenêutica. Trad. de Vera Portocarrero. Rio de Janeiro: Forense Universitária, 1995. 
FOUCAULT, M. Retornar à História. In: FOUCAULT, M. Arqueologia das Ciências e História dos Sistemas de Pensamento. Ditos e escritos II. Rio de Janeiro: Forense Universitária, 2000 p. 282-295.

FOUCAULT, M. Vigiar e punir: nascimento da prisão. 42. ed. Petrópolis: Vozes, 2014.

GREGOLIN, M. R. V. O dispositivo escolar republicano na paisagem das cidades brasileiras: enunciados, visibilidades, subjetividades. Revista Moara, Belém, Edição 43, p. 6-25, jan.-jun. 2015. Doi: https://doi.org/10.18542/moara.v1i43.2633.

Nota do PSOL: Marielle presente! Disponível em: http://psol50.org.br/nota-do-psol-mariellefranco-presente/?fbclid=IWAROAJO3Chmv-

OxNYztNq7C2hx3vfTY1Ut9eqX7Fy442IQEVzRGANLy2mell. Acesso em: 26 abr. 2019.

RAMOS, A. de C. Curso de Direitos Humanos. São Paulo: Saraiva, 2018.

RANGEL, S.; VETTORAZZO, L.; FRANCO, L. Vereadora do PSOL é morta a tiros no Rio de Janeiro. Folha de São Paulo, 2018. Disponível em: https://www1.folha.uol.com.br/cotidiano/2018/03/vereadora-do-psol-e-morta-a-tiros-nocentro-do-rio.shtml. Acesso em: 25 out. 2019. 